\title{
¿Qué significa creer en los seres humanos?
}

\author{
Carlos Eduardo Maldonado*
}

Recepción: 16 de octubre de 2012 • Aprobación: 11 de diciembre de 2012

\section{esumen}

Este texto constituye una reflexión acerca de uno de los problemas fundamentales de la existencia y la filosofía, sin embargo, muy pocas veces explorado de manera sistemática: ¿qué significa creer en los seres humanos? A partir del reconocimiento explícito de que existen múltiples tipos de humanismo, se busca combinar elementos provenientes de la literatura y la historia, la filosofía y la política, principalmente, con dos fines: por un lado, comprender, explicitar bien en qué consiste el problema; por otro, intentar responder a la pregunta. La reflexión reconoce que en el mundo actual existen numerosas razones que permiten, fácilmente, no evitar una respuesta al problema formulado, sino, más bien, desviar la carga o la fuerza de la preocupación. Mientras que se señalan estas razones, se hace un llamado a situar la mirada reflexiva en el foco del problema. Creer en los seres humanos implica, de entrada, confiar en las posibilidades que ofrece la diversidad humana, creer incluso en lo imposible, en la vida y, a pesar de sus circunstancias, en la facticidad misma y obras de los propios seres humanos, como las normas y los poderes, los sistemas y las estructuras. A lo largo del texto se ilustran y evalúan diversos argumentos, para, hacia el final, sugerir que, de cara al presente inminente y al futuro, la pregunta adopta un tono agónico. Este tono implica la transformación misma del espíritu y del talante de la filosofía, y más allá de ella, de lo que signifique el humanismo.

Palabras clave: tipos de humanismo, diversidad humana, vida, trabajo humano, transformación. 


\section{What does it mean to believe in human beings?}

\section{Abstract}

This paper presents a reflection about one of the fundamental problems of existence and philosophy that is seldom systematically explored: what does it mean to believe in human beings? From the explicit recognition of multiple types of humanism, elements from literature and history, philosophy and politics are sought to be combined mainly with two purposes: first, to understand and explain well what the problem is, and second, to attempt to answer the question. The reflection recognizes that in today's world there are numerous reasons that do not allow easily avoiding an answer to the formulated problem, but, rather, diverting the load or strength of the concern. While these reasons are identified, there is a call to place a reflective look at the focus of the problem. Believing in human beings involves, first, trusting the potential of human diversity, even believing in the impossible, in life and, despite their circumstances, in factualness and the works inherent to human beings, as well as in rules, powers, systems and structures. Throughout the text, various arguments are illustrated and evaluated for, towards the end, suggesting that, for the imminent present and the future, the question takes an agonized tone. This tone involves the transformation of the mind and spirit of philosophy, and beyond that, of what humanism means.

Keywords: types of humanism, human diversity, life, human labor, transformation. 


\section{Que signifie croire aux êtres humains?}

\section{Résume}

Ce texte est une réflexion critique sur un des problèmes fondamentaux de l'existence et de la philosophie, mais, peu de fois exploré de manière systématique: que veut dire croire aux êtres humains? En partant de la reconnaissance explicite du fait qu'il existe plusieurs types d'humanisme, le but est de combiner des éléments de la littérature, de l'histoire, de la philosophie et de la politique, principalement, avec deux objectifs: d'une part, comprendre, bien expliciter ce sur quoi porte le problème; d'autre part, essayer de répondre à la question. La réflexion reconnaît que dans le monde actuel il existe de nombreuses raisons qui permettent, facilement, de ne pas éviter une réponse au problème formulé, mais, plutôt, d'éluder la charge ou la force de la préoccupation. Tandis que ces raisons sont signalées, un appel est fait pour tourner l'attention de manière réfléchie sur le centre du problème. Croire aux êtres humains implique, d'entrée, faire confiance aux possibilités offertes par la diversité humaine, croire à ce qui est impossible, à la vie et, malgré ses circonstances, à la facticité même et œuvre des êtres humains, telles les normes et les pouvoirs, les systèmes et les structures. Tout au long du texte sont illustrés et évalués différents arguments, pour, vers la fin, suggérer que, face au présent imminent et au futur, la question adopte un ton agonique. Ce ton implique la transformation même de l'esprit et de l'humeur de la philosophie, et plus loin d'elle, de ce que veut dire l'humanisme.

Mots-clés: types d'humanisme, diversité humaine, vie, travail humain, transformation. 
Contra lo inverosímil, cabe hoy preguntarse acerca de la importancia, la necesidad, la urgencia o la posibilidad de confiar en los seres humanos. Una consideración a todas luces anodina, si se la mira con los ojos del pasado. Creo que la cuestión que aquí planteo tiene la máxima envergadura de un problema que abarca al mismo tiempo a la filosofía y a la ciencia, a la ética y a la lógica, pero que las desborda también con mucho, como lo mostraré gradualmente.

Atrás queda la época de los sustos acerca de la muerte de Dios. "Si Dios ha muerto, todo es posible", escuchamos alguna vez. Heidegger se destacó, en su momento, por desarrollar, particularmente en la segunda mitad de su vida y su obra, una filosofía centrada en saber preguntar, en cuestionarse. En su caso, se trató de preguntas metafísicas en torno al papel de la técnica, acerca del ser y del pensar, por ejemplo, siempre interrogaciones que acusaban la historia del olvido del ser en la historia de Occidente, las consecuencias de dicho olvido y abandono y la posibilidad de (re)encontrar al ser. Con tono propio y en un contexto y con finalidades diferentes, Merleau-Ponty también adelantó un modo de reflexión de espíritu eminentemente erístico, a la mejor manera de Sócrates.

Vivimos un mundo en el que los hechos más inimaginables han sido efectivamente posibles: desde Auschwitz y Buchenwald, hasta Guantánamo y Abu-Ghraib; desde la violencia intrafamiliar y el bullying, hasta la pederastia de los guardianes de la palabra de Dios; desde el salvamento de los bancos y el sector financiero en desmedro de la sociedad y de la gente misma, hasta la acumulación de un arsenal biológico, químico y atómico que podría destruir varias veces toda la vida del planeta. En verdad, la lista podría hacerse muy larga y cada vez más dolorosa. En ella podría incluirse la indolencia del sistema de salud que se encuentra en crisis a nivel mundial, la negación del derecho internacional y la proliferación de fuerzas paramilitares facultadas para llevar a cabo toda clase de crímenes en favor del Estado, el orden y la institucionalidad, aquí y allá.

Hemos ganado en información, que es la materia prima para una ciencia políticamente incorrecta: la historia. Hemos ganado información, y con ello, también, pero de manera indirecta o como valor agregado, hemos 
ganado memoria. Pues bien, un sistema que gana información —aunque no necesariamente memoria- es un fenómeno no-lineal. Su complejidad es directamente proporcional al proceso mismo: a) mediante el que gana información; b) a través del cual procesa información.

Hemos ganado información acerca del carácter sistémico y sistemático como en el mundo se vienen produciendo acciones cargadas de impunidad, actos que niegan la ética tanto como el derecho internacional, la diplomacia y la soberanía; en fin, los principios y valores más fundamentales y básicos de la existencia humana. Valores y principios como la vida, la libertad, la dignidad, la justicia, la equidad, la transparencia, la reciprocidad, el respeto y muchos otros más. Principios y valores que no son patrimonio absolutamente de nadie, de ningún credo o filosofía y que ni comienzan, de hecho, con los seres humanos ni tampoco terminan en ellos.

Esta serie de fenómenos, comportamientos y estructuras podría hacernos pensar que la Realpolitik ha llegado para predominar a escala global y sistematizada, que cada cual queda abandonado a su propio pellejo y que lo mejor que queda, pero en un sentido reactivo, es el mero Carpe Diem. Las grandes decisiones, al cabo, como ya lo pusiera en claro suficientemente desde la antropología (otra ciencia políticamente incorrecta) M. Douglas, son: a) decisiones institucionales; b) decisiones con ropaje institucional. A los seres humanos, en su individualidad y en su existencia cotidiana, les quedan las pequeñas decisiones. Pero las grandes decisiones -esto es, aquellas que implican vida o muerte; acaso, por ejemplo, empleo o desempleo, dignidad o vejación y vejamen, salud y enfermedad- son siempre decisiones institucionales. La primera maravilla y sorpresa del libro ya clásico de Douglas no es si las instituciones piensan, sino cómo piensan. A su manera, en el ámbito de la sociología, L. Coser había hecho explícito que las instituciones son (esto es, piensan) voraces (con voracidad); es decir, solo se saben y se quieren a sí mismas, y relegan todo lo demás a simples medios e instrumentos para su reproducción y beneficio.

En la historia de la humanidad, situaciones semejantes han acontecido reiteradamente. Tal fue el caso de la Inquisición o las pestes negra y 
bubónica, la imposición del Ancient Régime en la Europa del siglo XIX o el advenimiento del nazismo, el fascismo y el nacional-cooperativismo. Y esto, en perspectiva eurocéntrica, pues los crímenes mil veces denunciados contra comunidades indígenas en nuestra América y en África, por ejemplo, o el crimen contra la naturaleza y la sobreexplotación de esta hasta límites inimaginados pueden y deben ser también tenidos en cuenta y recordados continuamente. Al decir de Goody (2006), asistimos a una civilización, Occidente, que se caracteriza por el robo de la historia de otros pueblos, sociedades y culturas. No es simplemente que la historia la escriban los vencedores, lo cual a estas alturas es un verdadero truismo, sino, peor y muy documentadamente, cómo la historia y la memoria, las experiencias y la vida han sido robadas y desplazadas, consiguientemente, a lugares oscuros y escondidos.

El realismo se impone por todas partes y tiene sus propias expresiones y lenguajes. Desde la Red Eschelon que vigila y controla todas las comunicaciones en el planeta, hasta los hombres de gris, los de verdad, que representan, por ejemplo, al Banco Central Europeo, no aquellos otros de La historia interminable de Michael Ende, en la literatura que amenazan a fantasía y contra la cual solo los niños pueden librarnos. Y el realismo significa cada vez más obliterar la fe y la esperanza, una muestra de lo cual son los recurrentes pero sordinos llamados a la confianza, en sus diversos nombres: capital social, capital humano, capital intelectual, por ejemplo. ¿El Banco Central Europeo, dije? Esta no es sino la expresión regional de lo que para América Latina es el Banco Interamericano de Desarrollo y cuyos pilares son, en realidad, el Fondo Monetario Internacional, el Banco Mundial y la Organización Internacional del Comercio: la "maldita trinidad" ("the unholy Trinity", al decir de Peet, 2003).

Contra el realismo —que se expresa por ejemplo en la Realpolitik (es decir, el mundo de los intereses creados, los grupos de presión, la muerte de "verdad" como la primera víctima de una sociedad sistémica y sistemáticamente aquejada por toda clase de conflictos y violencias)—, cabe decir, por lo menos, el problema: ¿podemos (aún) confiar en los seres humanos, a pesar de tantas estructuras e instituciones tan... 
esencialmente inhumanas? De manera breve y directa: ¿qué significa creer en los seres humanos?

No pretendo aquí suministrar una lista de respuestas o de significados. Antes bien, me propongo, ante todo, comprender, abordar, identificar e intentar resolver un problema. Es, para decirlo de manera sucinta, a mi modo de ver, el principal problema que queda en tiempos borrosos -líquidos, como ha sostenido, con acierto, Bauman-.

Creer en los seres humanos significa creer, de entrada, en la diversidad que somos, pues no se trata de creer únicamente en tal o cual persona en particular; tampoco se trata de confiar en una clase determinada de seres humanos, dependiendo de las tipologías que se asuman y justifiquen. Existen siempre sorpresas buenas y paisajes inexplorados acerca de los otros y de nosotros mismos. En este sentido, se trata de una experiencia, a saber: abrirnos a los paisajes inexplorados que son los otros, aunque ello no significa, en manera alguna, abrirnos de manera indiscriminada y acrítica. Al fin y al cabo, los seres humanos se caracterizan por la diversidad, la pluralidad, la diferencia y, en consecuencia, por ser una promesa siempre por cumplir, un paisaje por explorar, una experiencia por vivir.

En verdad, la marca de calidad de la naturaleza, como de la vida misma, está en la diversidad, la pluralidad, no en la unicidad y el unanimismo. $\mathrm{Ni}$ siquiera, como a su manera lo sostuviera con acierto Muguerza, se trata de creer en las mayorías — ¡horribile dictu! - : los seres humanos somos intrínsecamente plurales y debemos siempre bendecir a la Torre de Babel — que debe ser leída como algo distinto a un castigo-, pues nos abrió posibilidades de descubrimiento siempre inacabadas, permanentemente abiertas, en el espacio y en el tiempo. Desde el lenguaje hasta la cultura, desde el sexo hasta las creencias, desde las experiencias hasta los sueños, desde las geografías hasta las biografías y los entornos propios de cada quien: los seres humanos, en su diversidad, son esencialmente irreductibles. No son reductibles ni siquiera cuando elaboramos acerca de ellos patrones o etiquetas, grupos o segmentos. 
La diversidad humana constituye, a todas luces, la marca distintiva de la complejidad que somos; pero la complejidad implica pensar y vivir en términos de sistemas esencialmente abiertos, intrínsecamente indeterminados e inacabados, en fin, incompresibles y en continuo acabamiento-sin-lograrlo. La irreductibilidad de la pluralidad humana equivale exactamente al reconocimiento y la experiencia de descubrimientos — pensamos, siempre buenos- que no pueden ser recapturados por el pasado.

Desde este punto de vista, la principal dificultad de creer en los seres humanos es esa nefasta tendencia a etiquetar, encasillar, definir y catalogar que, en realidad, equivalen a cerrar el descubrimiento a lo ya conocido, lo ya experienciado, lo ya vivido. La cultura ha hecho a los seres humanos cautelosos y prevenidos, realistas y desconfiados. La cultura, según parece, es intrínsecamente conservadora. Se trata, en verdad, de la amenaza consistente en el determinismo histórico y cultural, es decir, la creencia de que el pasado anticipa y contiene, total o parcialmente, el futuro.

Creer en paisajes inexplorados significa exactamente creer en lo imposible, en la vida, en los seres humanos a pesar de sus circunstancias, de la facticidad y de obras suyas como las normas y los poderes, las estructuras y los sistemas, por ejemplo. Se trata, sencillamente, de creer en la libertad y la osadía, en el desafío y en la imaginación. En una palabra, creer en la esperanza.

Sí: pensar estructuras imposibles. Esto ha sido posible gracias, por ejemplo, a las matemáticas que han desarrollado un capítulo que se llama la cohomología, que se dedica al estudio de estructuras imposibles. Pero ya el arte, el diseño y la arquitectura han convertido lo imposible en temas explícitos de trabajo. Escher o Koolhaas, por ejemplo. Atravesando las matemáticas, hasta las artes, y de la filosofía a la vida podemos pensar, vivir y apostarle a estructuras, situaciones o tiempos imposibles. Eso es lo que nos hace irremisiblemente humanos.

Como una referencia, creer en los seres humanos significa, análogamente al joven Siddartha Gautama, desconfiar de las apariencias y confiar en que podemos superar lo inevitable: la enfermedad, la vejez y la muerte, 
que son, según parece, los mayores desafíos que podemos pretender. Al fin y al cabo, ha quedado ya claro desde la antigüedad que la talla nuestra se mide por el tamaño de los retos y desafíos que nos proponemos. Pero si ello es así, entonces la combinación de imaginación y voluntad se tornan en dínamos de la vida misma.

Creer en los seres humanos significa saber que cuando se ha perdido, aún queda la ebriedad — hybris - y cabe entonces, acaso, actuar por desespero, sin esperanzas, y encontrar la esperanza en la acción misma. Se trata de un acto de confianza consistente en un abandono y solidaridad, tan vieja como los primeros primates, como ya Gordon Childe nos lo puso de manifiesto, y con él, la arqueología y la paleontología, la antropología y la filosofía. Y por su parte, Frans de Waal ha puesto suficientemente de manifiesto que la experiencia de la solidaridad —que es por definición esencialmente gratuita- no es única de esa especie que es el homo sapiens sapiens, sino que, por el contrario, se remonta, por lo menos, a los mamíferos superiores. Al fin y al cabo, por ejemplo, la teoría de juegos puso de manifiesto que en determinadas circunstancias, la mejor manera de ser racional y tomar decisiones racionales consiste, en ocasiones, en ser irracionales. El término que le asigna en la teoría de juegos a esta clase de situaciones es la de loterías. Solo hay que subrayar que todo depende, siempre, del momento y la estrategia; no se trata, en absoluto, de sostener que la irracionalidad — acaso la fe— es una estrategia válida sin más y para siempre.

Una serie de experiencias acumuladas en el tiempo y muchas situaciones cotidianas pudieran dar la impresión de que, debido quizás al peso de la información, los seres humanos descreyaran de los demás y, más específicamente, de las capacidades que las organizaciones e instituciones humanas parecieran empeñarse en erosionar. Pareciera imponerse la indolencia, la burocracia, la apatía y la anomia generada por la propia institucionalidad.

Es normal no creer en toda la gente - a veces-, pero no de todos y cada uno. Pero desconfiar de la gente, sin más, es patológico por completo. En ese caso, el espíritu está mal. Y así, la vida, al cabo, no se hace más posible. 
Justamente, ante tales circunstancias, creer en los demás consiste en saber que por amor somos capaces de lo imposible, jy más! Somos capaces de superar enfermedades terribles y de hacer que la flecha del tiempo que marca en dirección a la entropía sea reversible. Significa, en suma, vivir la ausencia de límites, barreras y fronteras. Solo quienes viven descreídos —en sí mismos o en los demás - ven barreras y bordes, y viven en ellas.

Los milagros suceden todos los días. Aunque no los vemos, aunque no tengamos nombres para ellos. Solo que por la expresión milagros no hay que pensar en nada mágico o confesional, y en mi particular modo de verlo, nada teológico, sino, sencillamente, en pequeñas maravillas que acontecen de manera gratuita. Al fin y al cabo, confiar en los demás no es nada más ni nada menos que un acto de gratuidad. Caben, desde luego, buscar siempre razones $y$, por tanto, justificaciones. Pero ello no debe confundirse con un proceso de racionalización a la manera como se habla en psicoanálisis, por ejemplo.

Vivimos y hemos vivido guerras justas e injustas (Walzer), humanidad e inhumanidad (Glover), con tonos y acentos disímiles y variados: Buchenwald, el paramilitarismo, la carnicería animal (Coetze), entre muchas otras; las dictaduras, el neocolonialismo y los imperialismos variopintos; el crecimiento y el desarrollo económicos, la indulgencia del sistema financiero y la impunidad del capitalismo financiero; el apartheid, las matanzas étnicas y las muertes lingüísticas, en fin, la indiferencia en la forma de cocooning, la alienación que significa y que produce el consumismo; al cabo, ulteriormente, la banalización del mal, para decirlo con Arendt.

Cabe pensar que cada época piensa, con la mediación de un gran autor, los conceptos y categorías que debe pensar para su momento y que los eleva a rangos universales, aun cuando situaciones semejantes pudieran, como es efectivamente el caso, encontrarse en otros momentos de la historia. Pues bien, una categoría específicamente contemporánea es la de situaciones límites, que le debemos a Jaspers y se proyecta a través del existencialismo, más allá de esta escuela filosófica hasta las artes. Cuando se vive una vida banal, de desasosiego - en el sentido en que lo traza Pessoa, notablemente-, de tedio y aburrimiento, como lo pinta 
Lévinas; a su manera, una existencia en la que lo único cierto y seguro es que, alguna vez, en algún momento acaecerá la muerte; en una situación semejante, lograr creer en alguien constituye a todas luces una experiencia límite, esto es, una experiencia que cambia radical, estructuralmente el decurso de nuestra vida. Nunca, jamás volveremos a ser los mismos una vez que no hemos creído en nadie, y una vez que hemos tenido la experiencia de la confianza — que es, por definición, ciega, gratuita-.

Pues bien, las situaciones límites pueden ser comprendidas como expresiones de las potencias del ser humano. Esas potencias que algunos autores llamarán como —o incluso situarán en- el alma, la voluntad, el cuerpo o el espíritu, para citar los casos más conocidos.

A la mención acerca de la solidaridad cabe agregar dos adicionales, en planos y contextos diferentes. Una es la de la hospitalidad, que se halla en la base del encuentro con el extranjero, el extraño, aquel a quien seguramente no se volverá a ver. La hospitalidad, en su sentido originario, nada tiene que ver con el turismo y la hotelería, sino con la atención que merece el encuentro fortuito con alguien a quien seguramente jamás volveremos a encontrar y que, sin embargo (ipor eso mismo!), merece la mejor atención y cordialidad. Esta es una expresión de nuestro sentido humano.

En verdad, la hospitalidad hacia quien seguramente se volverá a ver o a encontrar deja de ser tal: se contagia, más o menos, de interés, de aprovechamiento, incluso de oportunidad de negocio. La hospitalidad es una experiencia radical, porque no existe la seguridad de volver a encontrar a quien es objeto de nuestras mejores atenciones. El presente se impone, entonces, como una experiencia eterna.

A la solidaridad y la hospitalidad se aúna, en segundo lugar, el amor. Una experiencia que no siempre ha sido universal, y que acaso no tenga por qué serlo.

En verdad, creer en los seres humanos significa creer que el amor todo lo puede, y puede incluso más allá de la muerte, puesto que es lo único 
que vence a la muerte; nos lo han enseñado poetas y literatos. El amor de una madre por sus hijos, el amor de un hermano por otro, el amor de un hijo por sus padres, por ejemplo. Por el amor somos capaces de los más ignotos sacrificios, y un límite imaginable no se avizora aún en la historia de lo posible del ser humano.

Al respecto, vale recordar que entre los griegos la amistad era una experiencia más fundacional de comunidad — koinonía - que el amor. Ser griego significa creer en la amistad, y no en el amor, porque este es volátil y perecedero o pasajero, en tanto que la amistad no conoce de barreras. Solo con la llegada del cristianismo, el amor logra ocupar un papel protagónico, pero las proporciones se invierten entonces. En efecto, con el cristianismo, la experiencia del amor se superpone a la de la amistad y la desplaza. Ser cristianos, en verdad, significa confiar en el amor y descreer en la amistad, sorpresivamente, con los mismos argumentos que lo contrario sucedía entre los griegos antiguos.

De esta suerte, en Grecia, creer en los demás es un acto fundacional de amistad - filía, ágape-, en tanto que para los cristianos se trata de un acto de amor, y no de amistad. Se trata, a todas luces, de experiencias culturales que imponen valores humanos y que los quieren leer, en consecuencia, como trascendentales, cuando no son tales, y no de manera necesaria o unívoca. Por esta razón no quiero fundar el acto de confianza en los otros en la amistad más que en el amor, o en este más que en la solidaridad. Ambos son solo expresiones de un fenómeno definitivamente más radical y fundante.

Existen formas llamadas anormales de humanidad que nos confrontan con nosotros mismos: el sufrimiento y el oprobio, la enfermedad y la locura, el abandono y la niñez, la senescencia y la decrepitud. Pero ninguna de ellas hace otra cosa que revelarnos otras posibilidades de nuestra existencia. No sin razón Foucault ha acusado cómo lo habitual ha sido encerrarlas y proscribirlas, desde la stulftifera navis, hasta los manicomios y las prisiones, desde los sitios de encerramiento y clausura que nunca aparecerán como sitios de atracción turística; en contraste con cementerios, como 
Arlington y Père Lachaise, La Recoleta o el Cementerio Protestante, por mencionar tan solo los más famosos.

El más apasionante y difícil de los problemas relativos al convivio consiste en esclarecer - intelectual y experiencialmente-cuál es el sentido o la contribución que la anormalidad hace a la constitución de un mundo común y normal para todos. Filósofos y artistas, poetas y escritores, líderes espirituales y hasta políticos y sociales han batallado alguna vez con este problema. Las respuestas han sido plurales y, por tanto, disímiles. Lo cierto es que la anormalidad sí contribuye a la constitución de un mundo normal y común para todos, mostrándonos, si cabe la expresión, la cara oculta de la luna. De esta suerte, en contraste con el anatema y el ostracismo, la reclusión o la eliminación - que es lo que han hecho esos regímenes que son, en consecuencia, violentos, dictatoriales y excluyentes-, debemos y podemos convivir con la anormalidad como con otra forma de ser de nuestra existencia. Parodiando el decir de Sartre, cuando sostiene que una de esas formas de anormalidad era Genet, si el genio no es un don sino una de las maneras como nos inventamos a nosotros mismos en casos desesperados, asimismo la experiencia de la anormalidad es una de las formas como logramos inventarnos a nosotros mismos, gracias a esos casos desesperados. Lo que sucede, para los más, es que cierran los ojos, dan la espalda o acallan sus oídos a la anormalidad — por temor, acaso, de confrontarse con ellos mismos-. En contextos y lenguajes diferentes, es lo que acontece en la poesía de Sor Juana Inés de la Cruz, por ejemplo.

Sabemos que hay gente irredenta. Conocemos incluso a varios que no merecen nuestros afectos. Sin embargo, debemos poder reconocer que se trata de gente cuyas posibilidades fueron limitadas o quedaron truncas; son lo que son, a pesar de sí mismos, incluso lo son en contra de sí mismos, sin que ellos mismos lo sepan. En algún mundo ideal o paralelo pueden llegar a ser distintos, pero como ellos; también nosotros mismos podemos o podríamos llegar a ser distintos de lo que somos... Radicalmente distintos.

Y es que creer en los demás significa aceptar la posibilidad de que podamos cambiar y dejar de ser lo que habíamos sido hasta la fecha; o 
bien, que podemos vivir como siendo distintos de lo que habíamos sido hasta entonces. Creer, confiar, en suma, no es un acto: es un proceso de metamorfosis continuada.

En verdad, lo que emerge en el proceso, en la experiencia mediante la cual logramos creer en otro(s), en sus palabras o sus acciones, en sus promesas o en su presencia, en su existencia misma, es, a la postre, la acción de la voluntad de vivir. Notablemente, se trata de la capacidad para no dejar que una primera impresión creativa se diluya en el tiempo, en la obviedad y en la banalidad del día a día, para que se convierta en nutriente de sueños, acciones y posibilidades. Solo los seres humanos que crean posibilidades -incluso contra la imposible — podrán (como lo señala García Márquez) tener una segunda oportunidad sobre la tierra.

Creer en los seres humanos significa descubrir algo de lo nuestro en los otros, algo que logra conmovernos: movernos, descubrir un cierto aspecto de nosotros mismos. Con ello, sorpresivamente, al creer en los otros, logramos descubrir la básica posibilidad, hasta entonces acaso desconocida, de que somos nosotros los que podemos creer y confiar en los otros y gracias a ellos, pero desde nosotros mismos. Creer en los demás es un descubrimiento de nosotros mismos como de la capacidad de cerrar los ojos - por un momento o de manera definitiva_ y abandonarnos al otro o los otros. Una mujer, un amigo, un hermano, la madre o alguien más, según el caso. Creer en la alegría de los niños, en la sabiduría de los ancianos, aunque hayamos perdido aquella y no escuchemos o nos aburra esta... o estos.

Creer en los seres humanos implica un cierto principio de sabiduría: saber vivir consigo mismo, saber vivir con los demás. Este fue, desde siempre, el objetivo de la ética y, más amplia y fundadamente, el tema de la filosofía. La filosofía, al fin y al cabo, ha consistido en alcanzar una cierta clase de sabiduría; aquella, la ética, es una sabiduría práctica — que es el problema mismo del convivio-. Esta, una sabiduría, además teórica, consistente en temas tales como: saber qué temer y qué no, saber si hay y cómo son los límites, y si no los hay, qué se sigue de ello, saber qué es el mundo y la naturaleza, cuál es nuestro lugar en ellos, y qué se sigue de ello, por ejemplo. 
Pues bien, sostengo que, dado el decurso de los acontecimientos en el mundo de hoy, un tema nuevo para la reflexión filosófica es justamente este: establecer si podemos creer en los demás, qué significa ello y qué se sigue de dicha experiencia; incluso, en caso contrario, por qué ello no es posible y qué implicaciones ocurren o pueden acaecer entonces. En este texto, sencillamente he querido abrir una compuerta, hasta ahora inexplorada por la razón humana.

La ciencia -en particular la ciencia moderna, clásica - se convirtió en un asunto de especialización y alto tecnicismo. La ciencia moderna perdió el aire de sabiduría. Por ello mismo surgen, dados los fracasos filosóficos de la ciencia clásica, nuevas ciencias. Lo suyo consiste en retomar un segundo aire, por así decirlo, para acercarnos a la sabiduría.

Al fin y al cabo, la sabiduría no es algo que se sepa, sino que se vive. Yo, quienquiera que diga "yo", no soy racional o inteligente por lo que sé, sino por cómo vivo y qué hago con lo que sé. Mejor aún, la sabiduría no es algo que se enseñe; en el mejor de los casos podemos aprenderla. Y la fuente segura para ello es el ejemplo. Por eso, con el mejor tino y ojo aguzado, lo mejor que podemos hacer consiste en identificar alrededor nuestro gente sabia y acercarnos a ellos y aprender. Pero esto es algo que se dice fácilmente. No solamente porque hay muchos que pretenden sin serlo; y quienes lo son, como sostenía en otro contexto Nietzsche, caminan con pasos de paloma.

Un tema fundamental, pero altamente difícil: creer en los demás significa no juzgar. Vivimos tiempos críticos que nos han enseñado a juzgar a diestra y siniestra. El juicio es conveniente y necesario, sostengo, frente a instituciones y estructuras, pero no así, no necesariamente, frente a cada individuo con que nos encontramos en la vida.

Es claro que somos seres culturales; que, por tanto, toda lectura y visualización es ya una interpretación; es más, como lo pusiera de manifiesto Heidegger, vamos por el mundo cargados de pre-juicios. Jamás conocimos ni conoceremos lo que es la naturaleza, pues para nosotros ella se aparece siempre, inevitablemente, como interpretación, vía el sexo o la 
cultura, la raza o la religión, el poder o la economía, y demás. Sin embargo, debemos poder aprender a no juzgar.

No juzgar, no solamente porque no disponemos de toda la información completa, sino, además, porque aunque dispusiéramos de ella, aun no es seguro que podríamos ponernos en el lugar de los demás.

No juzgar no solo significa aceptar a los demás como son —algo que, a decir verdad, me parece muy poco-; más bien se trata de relacionarnos ante el otro como ante una pregunta, una promesa, un espacio abierto o una posibilidad. El juicio, por el contrario, es siempre cerrado y concluyente, cerrado y conclusivo. Del juicio solo se siguen dos cosas: un acto o el silencio, pues el juicio clausura la posibilidad del diálogo, de una experiencia abierta.

Es inmensamente difícil no juzgar. Quizás una parte de la sabiduría consista en ello. El juicio es severo y adusto, circunspecto y dilecto. No sabe de sonrisa o risa, no sabe de espontaneidad y autenticidad. Los más son los que, con buenos o malos argumentos, juzgan. Y precluyen así, un poco, la vida.

Como señala conclusivamente Fichte -en su famoso debate contra Kant-, "qué clase de filosofía se escoge depende de qué clase de hombre se es". Somos, por razones familiares, culturales, circunstanciales, sexuales o religiosas; o también, en otro plano, por razones nutricionales, políticas, antropológicas o étnicas, por ejemplo, determinados seres; y entonces, por ello, aun cuando no lo sepamos, elegimos los políticos que elegimos, los líderes que nos merecemos, en fin, las estructuras que aceptamos; o, en caso contrario, contra las que nos rebelamos y, al cabo, logramos echar abajo.

Hay una forma de confiar en los demás. Se trata de cuando podemos, en ocasiones, creer en los animales, generalmente las mascotas que nos rodean. En otras palabras, significa creer que los animales nos entienden y nos hablan y que podemos, a su vez, hablar con ellos y entenderlos. 
Creer que la naturaleza es nuestra amiga y madre y que siempre guarda la mejor para nosotros, al cabo.

En otro plano, escribe Coetzee (2001):

La plenitud de ser es un estado difícil de mantener en cautiverio. El cautiverio, el encierro en una prisión, es la forma de castigo por la que se decanta Occidente, que de hecho hace todo lo posible por imponerla en el resto del mundo mediante la repulsa de otras formas de castigo (las palizas, la tortura, la mutilación o la pena capital) consideradas crueles y antinaturales. ¿Qué nos sugiere esto sobre nosotros mismos? (pp. 41-42).

Las tres tareas más difíciles y de mayor envergadura en la vida son:

1. Lograr reconocer el propio destino.

2. Llevarlo a cabo, una vez que se lo ha reconocido.

3. Intentar cambiarlo, si es preciso, incluso aunque nunca se logre enteramente.

En verdad, hay que gente que lucha contra su destino, y triunfan. Son tantos casos conocidos y registrados en la literatura, la historia, la poesía y la filosofía, que, por ejemplo, nacen en un entorno y logran superarlo y superarse a sí mismos de lo que estadísticamente - esto es, inevitablemente- hubiera debido suceder. El azar no juega, en estos casos, un papel despreciable. Pero, con Nietzsche, la voluntad de vivir se erige como la luz de la existencia misma.

Asimismo, hay gente que, peor aún, lucha al lado, conjuntamente y en paralelo con su destino, y triunfan. Sus acciones se convierten en bisagras para nuevos bucles de retroalimentación positiva que disparan procesos de realización y exaltación generalmente poco conocidos entre los demás.

Una vez que se ha sufrido profundamente, que se han sufrido serias decepciones, que se ha padecido la violencia —que es, por definición, 
esencialmente gratuita—; una vez que se ha conocido el corazón roto, la vida quebrada, una gran pérdida o el cielo negro, ¿se puede (aún) creer en los demás? Para quienes no han conocido experiencias - experiencias límites - semejantes, la respuesta es clara, aunque, quizás no obvia. No así, sin embargo, para los primeros.

La vida no es perfecta, y está, ayer, hoy y mañana lejos de serlo. Creer en los demás significa, en realidad, considerar que sí se puede creer en los demás tanto como en la propia capacidad de creer en algo. ¿Cabe vivir en la desesperanza? Me resulta imposible imaginarlo. Vivir significa creer en quien nos ama o amamos, en quien conocemos o nos conoce, en fin, en quien no nos lastima y no lastimamos. La vida, a veces, se torna difícil, muy difícil, para algunos. Para otros, hemos recibido bendiciones, y acaso algún sufrimiento ha sido superado. Las cosas se superan en muchas ocasiones, gracias al tiempo. El tiempo, al cabo, es generoso y aporta solaz y permite alegría. Nos brinda una segunda, una cuarta, una vigésima oportunidad, a condición de que sepamos reconocerla y aceptarla, incluso sin dar las gracias.

Creer en los demás es quizás la más gloriosa de las experiencias de un auténtico renacimiento. Algunos, por su propio karma, necesitan o merecen renacer, lo cual les permite nuevas oportunidades de mejorar. Otros, en ocasiones, no requieren reencarnar porque en vida han comprendido —han amado, quizás han sufrido-y se han salvado a sí mismos o han sido salvados por alguna circunstancia fortuita, por definición pasajera y gratuita.

Una de las circunstancias más misteriosas pero maravillosas de la vida consiste en la gratuidad. Las cosas más maravillosas y extrañas de la vida son esencialmente gratuitas: la vida misma, la muerte, el amor y la amistad, la solidaridad y el sufrimiento, la alegría, la felicidad y la enfermedad, la salud, el hambre y el sueño, la inteligencia y la buena fortuna, por ejemplo. La gratuidad no implica abrirle una puerta al misterio o a la magia: es sencillamente uno de los nombres del azar o la aleatoriedad, las cuales, por definición, no conocen, no saben de reglas o leyes. Con toda seguridad, una de las dificultades cognitivas mayores para los seres 
humanos es el azar o la aleatoriedad. Quisiera decir que creer en los demás es efectivamente un acto aleatorio, que no responde a leyes ni normas, y no por ello es desdeñable.

El espacio de la gratuidad fue tradicionalmente la poesía y el arte, y la poesía ha sido, habitualmente, el lenguaje de la sabiduría. ¿Es sabio confiar en los demás, o no es, al cabo, otra tontería, una señal de ingenuidad e inexperiencia? ¿Puede asimilarse la sabiduría a la ignorancia y la inocencia? Nada parece responder en favor de esta conjetura. Por el contrario, todo parece indicar que la sabiduría se caracteriza por varios rasgos, aun cuando no siempre estén todos presentes: paciencia o alegría, determinación o espera, voluntad o conocimiento, soledad o aislamiento, que no son lo mismo.

Creer, en general, implica o se acompaña de un verso o un canto, de una chispa en la mirada o de un suspiro que traduce un segundo tiempo. Uno de los nombres de dios - no necesariamente con mayúsculas-es esperanza, y mientras tengamos esperanza, dios estará con nosotros, aunque no lo sepamos o no nos importe. Pero creer en los demás es algo por completo diferente a creer en una roca o una planta, un animal o un artefacto. Creer en los demás significa creer en una parte de nosotros mismos. Y no es, en absoluto, necesario que sepamos cuál parte nuestra es, o qué hace o de qué se trata.

La pretensión del torturador, advierte Sartre, su triunfo, consiste en llevarnos al límite en el que quisiéramos ya no existir. Pero como lo ponen de manifiesto campos de tortura desde Buchenwald hasta Abu-Grahib, desde Guantánamo hasta las mazmorras de la dictadura de Pinochet, por ejemplo, el torturado encuentra siempre maneras de salir airoso. Incluso refugiándose en la locura, que es la derrota última del torturador, no la muerte del torturado ni la delación.

Algunos animales pueden generar confianza en nosotros, particularmente algunos de los mamíferos superiores. No cabe, sin embargo, cerrar la puerta a priori a otras formas de vida. Empédocles decía que los dioses para los seres humanos son humanos, para las hormigas los dioses son 
hormíguicos, para las vacas son váquicos, para los delfines son delfínicos y para los helechos son heléchicos. Esta idea puede extenderse sin dificultad.

Si ello es así, creer en los demás significa creer en posibilidades como en formas, lenguajes y expresiones humanas o accesibles a los seres humanos.

Al revés, ¿es posible vivir sin creer en los demás o sin creer metafísicamente o en algunas ocasiones y circunstancias particulares en algunos? La literatura tanto como la historia, el arte tanto como la poesía, la filosofía tanto como la experiencia y el sentido común, todos apuntan a que es fácticamente imposible. Al final del día siempre habremos amado a alguien, y alguien nos habrá amado, alguien nos habrá hecho algún bien o, por lo menos, no nos habrá hecho algún mal. Y significa que la vida habrá valido la pena vivirla y que no fue en vano.

Terrible, en verdad, es para quienes en el momento final, o antes, la vida no haya tenido sentido. El escándalo, para los hombres, si no para los dioses o el dios, es que para algunos el final del día habrá sido así. Cuando ello sucede, en realidad, no solamente es un fracaso para quien vivió, sino para el dios mismo o los dioses. Pero si ello es así - isorpresa, escándalo! —, dios o los dioses son falibles. Lo cual rebaja notablemente su estatuto y valía.

En fin, no en última instancia se trata del reconocimiento permanente de que bien vale tener valor ético, pero también valor político, y que ambos no siempre se acompañan ni se implican recíproca y necesariamente. El coraje ético radica en poder vivir (la) verdad tanto como sus maltratos, sin descreer en ella. El coraje político implica poder mirar a los ojos a los demás sin ninguna clase de temor o de rencor, puesto que no han logrado que podamos dejar de creer... en nosotros mismos. En ello, podemos sostenerlo, consiste la historia moral del siglo XX y de lo que va recorrido del siglo XXI. Bastaría con echar una mirada a la historia contemporánea; la historia: esa ciencia políticamente incorrecta. 
Los verdaderos problemas en buena ciencia y filosofía no son aquellos que ocupan a todo el mundo. Por ello mismo es extremadamente difícil formular problemas y resolverlos. Por el contrario, los auténticos problemas morales son aquellos que implican excepcionalidad, diferencia, contraste y límite, no unanimismo o generalizaciones, siempre fáciles.

Creer en los demás es, pues, al cabo, confiar ante todo en la capacidad de la inventiva, la creatividad y el conocimiento que la cultura humana puede lograr. En efecto, no solamente hemos ganado una vida más, hemos ganado en esperanzas y en expectativas de vida, sino que también hemos avanzado significativamente en la reducción de la violencia, en la defensa de la vida, por ejemplo. No vivimos en un paraíso, ciertamente. El nirvana -iluminación consistente en el máximo grado de comprensión de las cosas en general- sigue siendo posible solo a nivel individual. Hemos logrado superar amplia, aunque no definitivamente, la historia de la logofobia, es decir, el miedo al conocimiento, el miedo a la investigación, el control de la libertad de pensamiento, la libertad académica y la libertad de expresión. Estos avances no son nunca llanos, planos o lineales, sino a través de paisajes rugosos adaptativos.

El peor de los futuros será siempre mejor que el mejor de los pasados por el solo hecho de que habrá posibilidades, esperanzas, horizontes. Al fin y al cabo, uno de los nombres de la divinidad o el absoluto es esperanza. Y jamás podremos renunciar a ella: creer, esperar incluso lo imposible, en determinadas ocasiones, como la única posibilidad plausible, sin claudicar.

Hay quienes tienen un umbral bajo al dolor y a la esperanza, a la capacidad de ensayar y equivocarse. Hay también quienes tienen un umbral alto al sufrimiento y la esperanza. Podemos pensar en pedagogías que aumenten estos umbrales. Y ellas pasan, con toda seguridad, por más y mejor conocimiento, más y mejores experiencias de transformación, mejoramiento y cambio. Pero más allá de estas pedagogías posibles - inunca enseñamos nada, solo, en el mejor de los casos, podemos aprender!-—, lo que queda es el ejemplo. Y sí: podemos aprender a creer en los demás observando a aquellos, que no parecen ser muchos, que han creído en los otros, incluso como en lo imposible mismo. 


\section{Referencias}

Arendt, H. (2006). Eichmann en Jersusalén: Un estudio sobre la banalidad del mal. Barcelona: Random House Mondadori.

Coetzee, J. M. (2001). La vida de los animales. Barcelona: Mondadori.

Cellini, B. (2007). Vida. Madrid: Cátedra.

Douglas, M. (1996). ¿Cómo piensan las instituciones? Madrid: Alianza.

García Gual, C. (1989). Los siete sabios (y tres más). Madrid: Alianza.

Glover, J. (2001). Humanidad e inhumanidad. Una historia moral del siglo XX. Madrid: Cátedra.

Goody, J. (2006). The theft of History. Cambridge: Cambridge University Press.

Nussbaum, M. (2011). Sin ánimo de lucro. Por qué la democracia necesita las humanidades. Madrid: Katz.

Peet, R. (2003a). La maldita trinidad: el Fondo Monetario internacional, el Banco Mundial y la Organización Mundial del Comercio. Navarra: Laetoli.

Peet, R. (2003b). The unholy trinity: The IMF, World Bank and Wto. Sudáfrica: Zed Books.

Pessoa, F. (2012). Plural como el universo. Plural como o universo. Medellín: Tragaluz.

Sartre, J. P. (1952). Saint Genet: Comedian et Martyr. París: Gallimard

Walzer, M. (2001). Guerras justas e injustas. Un razonamiento moral con ejemplos históricos. Barcelona: Paidós. 